\title{
Change Detection in the Amazon Rainforest with Radiometric Rotation Technique RCEN Multi-spectral Case Study: Guarayos - Bolivia.
}

\author{
H. Ferrufino Ugarte ${ }^{1}$; T. Zawila-Niedzwiecki. ${ }^{1}$; J. R. Santos ${ }^{2}$; F. D. Maldonado ${ }^{3}$ \\ ${ }^{1}$ University of Applied Sciences Fh - Eberswalde - Forestry Faculty \\ Alfred - Moller - Str.1 D - $16225 \quad$ Eberswalde - Brandenburg - Germany \\ \{hferrufino,tzawila\}@fh-eberswalde.de \\ ${ }^{2}$ INPE - Instituto Nacional de Pesquisas Espaciais \\ Av. dos Astronautas, 1758 CEP.: 12.227-010 São José dos Campos - SP., Brazil \\ jroberto@dsr.inpe.br \\ ${ }^{3}$ Instituto Nacional de Pesquisas da Amazônia - INPA \\ CEP.: 515 - 12245-970 - Manaus - AM, Brazil \\ maldonado@inpa.gov.br
}

\begin{abstract}
A working group of three institutions was set up to develop this study: University of Applied Sciences Eberswalde (Germany), National Institute for Space Research (INPE, Brazil) and National Institute for Amazon Research (INPA, Brazil). The main task is to apply in the Guarayos region (Bolivia), the multitemporal change detection algorithm "RCEN multi-spectral". The study area is located in Guarayos-Bolivia, characterized by two main high forests landscapes, "The Amazon Region" and "The Brazilian Paranaense Region"; the approach of the change detection is taken under multivariate analysis (three spectral bands), with data coming from two kinds of sensor ETM+/Landsat-7 and CCD/CBERS-2. The image detection was transformed from continuous image (floating-point) to thematic, through slicing and labeling process. Hence it is possible to discriminate five thematic classes: two related to degradation, two referring to regeneration and one of no-change. The change detection map shows: in the timeframe studied $11 \%$ of all area under study presents deforestation patterns, on the other hand the regeneration class is not significant. In conclusion the methodology has good performance and it is evolving in landscapes with high humidity complications.
\end{abstract}

Key words: change detection, degradation, CBERS-2, tropical forest, remote sensing, Guarayos.

\section{INTRODUCTION}

In the last decades Bolivia suffered high deforestation rates due to the exponential growth of the industrial agriculture. It is also suffering strong pressure by the landowners and by nonlandowners who do not respect the laws. The environmental legislation is not being respected mainly due to the institutional weakness and the lack of inspection. In this frame and considering, the Brazilian government's opening and release of imagery coming from the China-Brazil Earth Resources Satellite (CBERS-2), data is now provided to the South American community, completely free of cost, with rapid delivery (taking in the worst case only a few hours). This data is offered at the website
$<$ www.inpe.br>, which changes the reality of the developing countries that have little economic capacity, now enabling them to acquire current satellite imagery, under the agreement that each country will carry out evaluations of their section of the Amazon forest. In the same technological capacity building process, improving evaluation of disturbances to the Amazon forest cover, the countries are also offered unlimited access to semi-automated algorithms for the detection of changes in the Amazon forest [1] [2]. In this case study, a new algorithm is applied, which belongs to the family of the linear transformations, and is called the Change Detection Technique RCEN (Radiometric rotation controlled by a no-change axis multi-spectral) [2], [3] and [4]. This algorithm does not require radiometric pre- processing in any of its digital image processing. The technique in question does not require extensive training in the pre-processing works. Therefore we apply the algorithm in the tropical Bolivian rainforest which can be implemented to evaluate the change detection by regional offices of forest control in Bolivia.

\section{AREA UNDER STUDY}

The study area is located in the province Guarayos, in the northern part of the Department of Santa Cruz de la Sierra in Bolivia, limited with the Department of Beni. The total area under study reaches to 4,122 square kilometers, geographically the location coordinates are: from $15^{\circ} 55^{\prime} 09^{\prime \prime}$ to $16^{\circ} 28^{\prime} 22^{\prime \prime}$ South latitude and $63^{\circ} 25^{\prime} 21^{\prime \prime}$ to $62^{\circ} 47^{\prime} 27^{\prime \prime}$ West Longitude. Two main forest eco-regions involved are: "The Amazon Region" and "The Brazilian Paranaense Region". They present sub-regions: the first one is conditioned by the soil moisture regime with flooded and non-flooded forests[5], the second one has high trees known as "Semideciduo chiquitano" and "Guarayos region forest", which is a transition towards the humid Amazon forest [6], [7] and [8].

\section{METHODOLOGICAL APPROACH}

ETM+/Landsat-7 image for the first date 1 (Aug. $11^{\text {th }}$ 2001) and CCD/CBERS-2 images for the second date (July 20 ${ }^{\text {th }} 2006$ ) were used to understand the deforestation process, that is suffering the 
selected subset under study, Guarayos-Bolivia. The multivariate RCEN algorithm in our case uses the spectral bands red, green and NIR $(0.52-0.60,0.63-0.69$ and $0.76-0.90 \mu \mathrm{m})$. The methodological approach of the present study is subdivided in three parts as follows: pre-processing, application of the radiometric rotation controlled by no-change axis (RCEN), and the linear complementary operations. Finally the univariate image detection is obtained, sliced and labeled. The software in all the processing used was ERDAS Image.

The first step involves all the pre-processing work, in the application of multi-spectral RCEN, is not necessary to carry out the atmospheric correction, the process of noise minimization in the CBERS image was realized by the new algorithm "ISODATA Inversion" applied in the Amazon region [4]. Registration technique was carried out using a polynomial of first order with the method of nearest neighbor, to get a precision of 0,45 pixels, which represents in the normalized images a minor error of $14 \mathrm{~m}$, the spatial resolution was normalized to $28.5 \mathrm{~m}$. Due to the great trouble generated by the presence of water bodies was applied water masks, considering a mask with null values "0". This masking process avoided the bafflement effect of these bodies in the statistical procedures to get the image detection.

The second step started with the conversion of the integer number to floating point of de DN of both satellite images, as well as the application of multi-spectral RCEN [3], that is based in the obtaining of the angular parameters of rotation for each bitemporal pair, those angles are calculated in function of the axis formed by the straight line of regression of those points labeled in the field survey as no-change. This axis describes the correlation between pixels of no-change in the images of first and second date for each spectral band (green, red and NIR). The angular parameters of rotation $(\alpha)$ control the RCEN algorithm, which is obtained by calculating the arch-tangent of the slope of the regression line of no-change previously identified on the terrain. The rotation process generates intermediary images (rotated images), that is easily understandable following the mathematical expressions for the intermediary images.

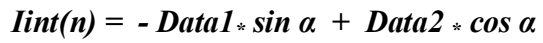

\begin{tabular}{|c|c|c|}
\hline $\begin{array}{l}\text { Where: } \\
\text { (n) }\end{array}$ & $\rightarrow$ & spectral band used $(2,3$ y 4$)$ \\
\hline Iint $(n)$ & $\rightarrow$ & intermediary image detection of the spectral band " $n$ " \\
\hline Data 1 & $\rightarrow$ & spectral band of date 1 of the same band \\
\hline Data 2 & $\rightarrow$ & spectral band of date 2 of the same band \\
\hline $\sin \alpha$ & $\rightarrow$ & sine of the angle of rotation of the same band \\
\hline $\cos \alpha$ & $\rightarrow$ & cosine of the angle of rotation of the same band \\
\hline
\end{tabular}

The third step, the complementary linear operations after the generation of 3 intermediary images, needs to interact for getting the image detection, although previously the intermediary images were affected for weights or proportions, that rest or increment the importance of this spectral band in the final interaction.

\section{$\operatorname{Iint}(\mathrm{bn})=[-($ bnData1) $\sin \alpha+($ bnData2) $\cos \alpha] *$ weight $(n)$}

Where: bn $=$ spectral band used

The intermediary images obtained for achieving a final change detection image, must interact after adapting to the new orthogonal axis, characteristic of the rotation; contributing with spectral peculiarities of change detection in a multidimensional space of " $n$ " variables, which denote the high variance contained in the 2 nd PC[9]. Then we applied to these new images the sum algorithm described in the following mathematical simple equation:

\section{Detection brute $=I$ int.B2 + I int.B3 + I int.B4 (format float)}

Where:

I int $=$ intermediary image

Hence, after the interaction of the intermediary images, we get the detection image derived of the integration of multi-sensor and multi-spectral data. Therefore the final process is completely independent to the rotation technique. It corresponds to the labeling and slicing, which is based on an univariate classification [3]. The result of the whole rotation and interaction process of the spectral components of change detection analysis, generates an image in gray tones $(\mathrm{DN})$, in continuous format, in which the changes in the landscape are outstanding. The image is then sliced and labeled in thematic format. The slicing and final labeling of the image detection was done, based mainly in the form of the frequencies histogram. In this histogram, the central maximum value shows the areas of no-change. The threshold classification, considered two patterns deviation as much to the left as to the right of the classification histogram. This is labeled in two classes of regeneration (moderate and high), two classes of degradation (moderate and high) and a class of no-change, whose borders and respective legend are based on the knowledge of the interpreter, and on the different levels and patterns of changes of the study area. The accuracy assessments have been done, by using kappa statistics.

\section{RESULTS AND DISCUSSION}

Figure 1 shows the dispersion of radiometric values derived from the image combination of the first date (August., $11^{\text {th }} 2001$ ) of ETM + and the second date (Jul., 20 $0^{\text {th }}$ 2004) of CBERS-2 (Figure 2). At the Figure 1 one observes the regression line that corresponds to the no-change pixels of vegetation cover, as well as the rotation angle for each bi-temporal pair. The application of the RCEN multi-spectral algorithm is controlled by the angular parameter of rotation, anti-clockwise of the orthogonal axis of the scatterplots of the image distribution (date $1=$ axis $X$ and date $2=$ axis $Y$ ) until axis " $x$ " becomes parallel to the no-change axis from the angle found.
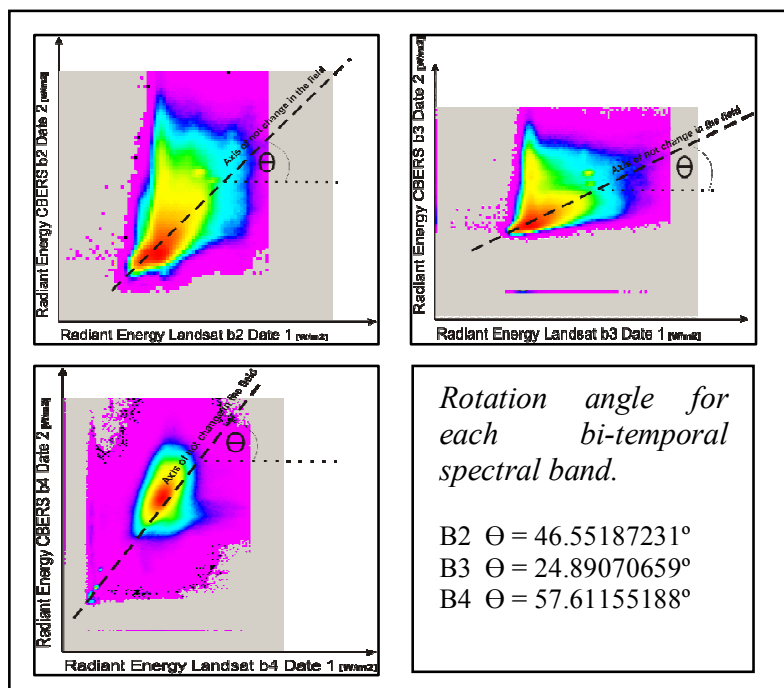

Figure 1. Scatter plot of radiometric values among ETM+/LANDSAT e CCD/CBERS-2 images and rotation angle of 2001 and 2006 images. 
Figure 3 shows, the slicing and final labeling of the image detection, based mainly in the form of the frequencies histogram (Maldonado, 2004). The result of this slicing and final labeling is shown in Fig. 3. In the graph one can see the advance of the anthrophic processes clearly. The masking procedure in this kind of landscape (flooded) must be carried out twice, before and after the process. This is to avoid the interference of the water bodies in the final calculation. According to extracted information of the detection image, it is observed that for the period of study (08/2001-07/2006), the class moderate and high degradation (both in this case considered as completely substitution of the forest cover by some other agricultural process such as soy bean, rice, corn, and grasslands), the main difference between high and moderate degradation is attributable to the moisture concentration in the different logged areas, because these areas shows major humidity content in the soil in comparison to other identified as deforested areas; for instance identified as high degradation. The deforested areas mean $11 \%$ of the total area studied $\left(4122 \mathrm{~km}^{2}\right)$. The high recovery is not significant because in both cases strong and moderate recuperation reaches totally of $0.92 \%$ of the area under study, mainly because these areas are completely new in relation to the advance of the agricultural frontier. So for instance there is not recovery areas. It is important to highlight that the route that crosses the study scene is relatively new (10 years). After the establishment of this new route the human pressure on the land is strong.

The accuracy of the change detection map, generated from the RCEN multi-spectral technique reach a Kappa value of 0.72 for a comparative analysis with ETM+/LANDSAT and CBERS data (from 2001 a 2006).

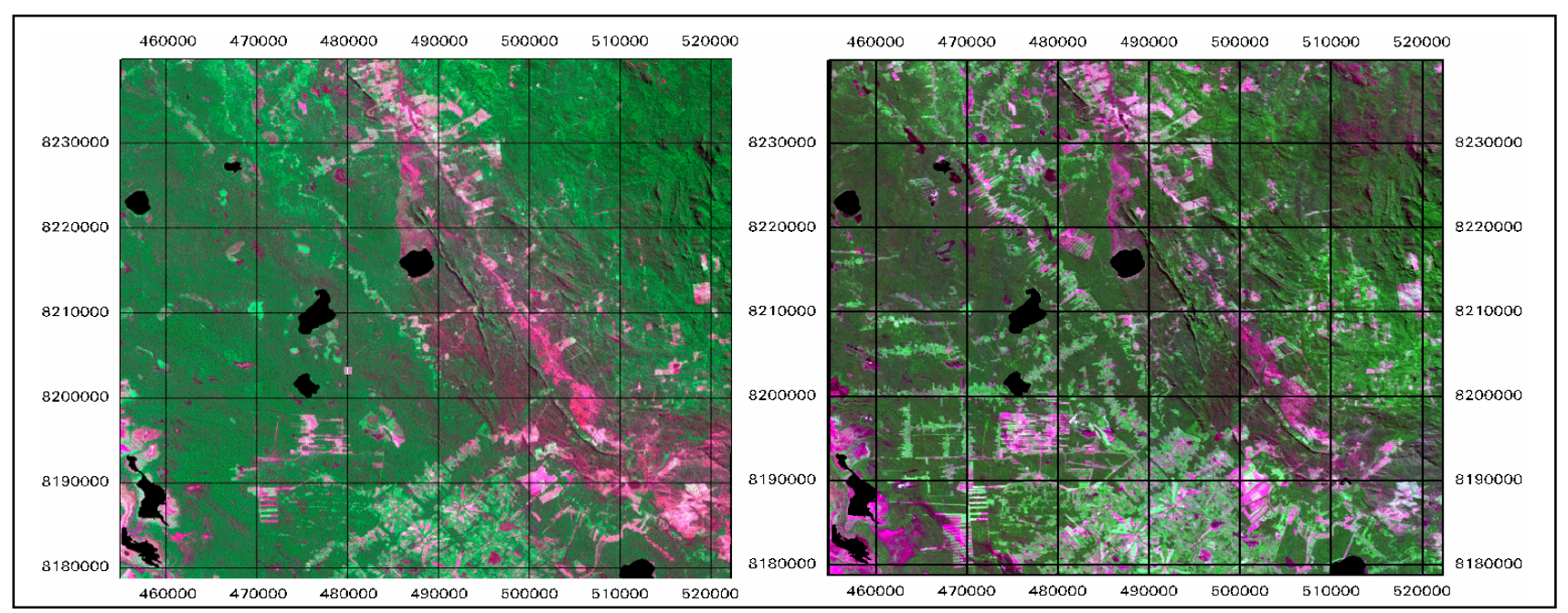

Figure 2. ETM+/LANDSAT, and CCD/CBERS-2 images (both in colour composite RGB, 342 ) of 2001 and 2006, respectively.

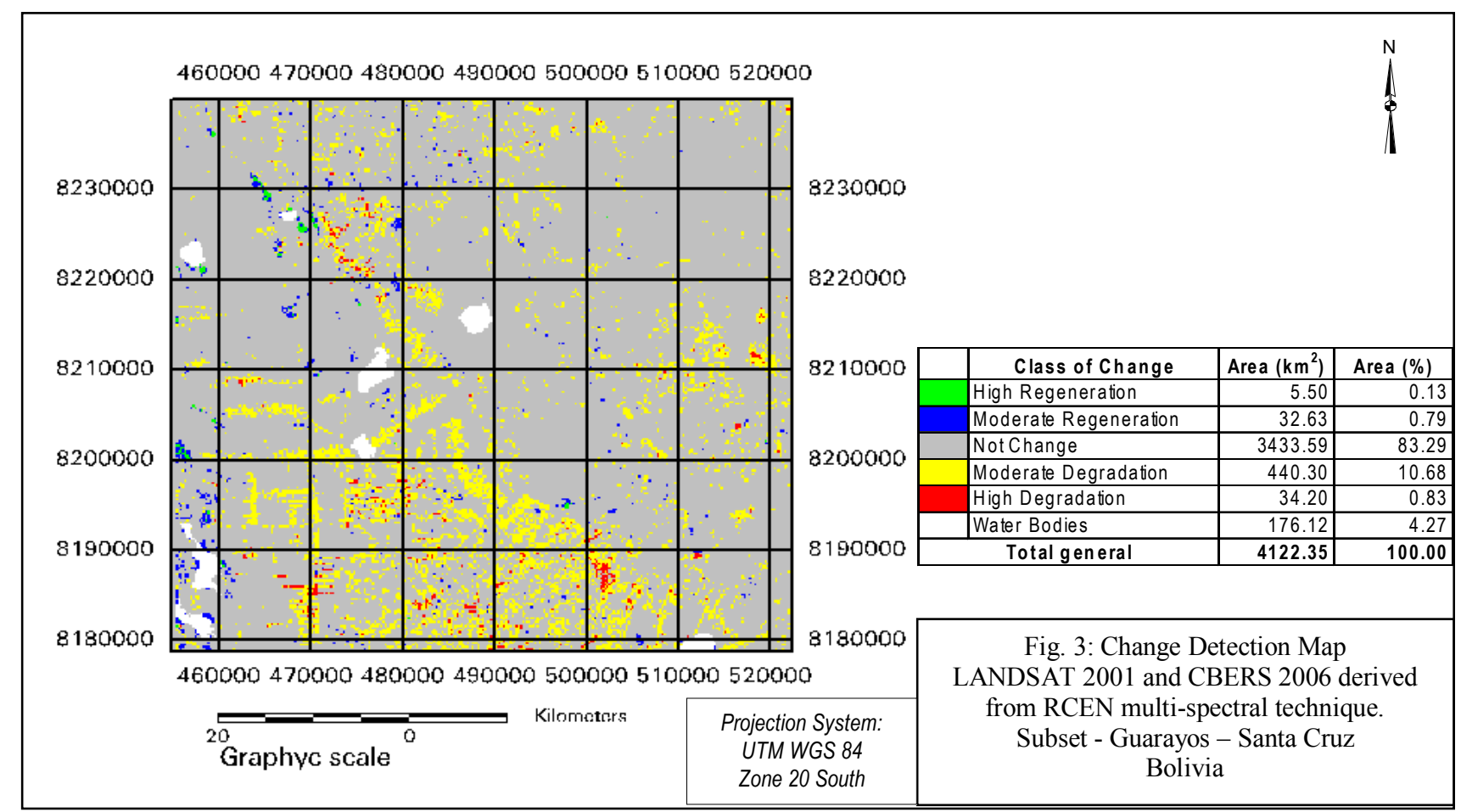




\section{CONCLUSIONS}

The RCEN multi-spectral technique allows one to obtain results without complicated radiometric correction pre-processing, minimizing the time of processing. The RCEN technique results can be obtained in a quick and simple form, with any combination of compatible spectral sensors, such as CBERS-Landsat. It is necessary, especially in areas such as those in this study, to mask the bodies of water, since in exercises carried out without masking the bodies of water are highly confusing and inaccurate results were produced.

In conclusion, the RCEN multi-spectral change detection technique should be made available for the community because the offer of satellite information by the Brazilian government opens the doors to the community researchers, who require such methods to fill information gaps. This technique can be support law enforcement personnel and natural resource managers in large areas such as the Amazon Basin, specially in Bolivia.

\section{ACKNOWLEDGMENT}

The authors acknowledge to CNPq and FAPEAM for the research grants; the INPE, INPA (Brazil) and University of Applied Sciences (Germany) for the logistic support in this study.

\section{REFERENCES}

[1] P. Coppin, I. Jonckheere, K. Nackaerts, B. Muys, and E. Lambin. Review article digital change detection methods in ecosystem monitoring: a review. International Journal of Remote Sensing, v. 25, n. 9, p. 1565-1596, 2004.

[2] F.D. Maldonado, M. Martinelli, and V.C. Carvalho. Innovaciones y mejoramientos de las técnicas de detección de cambios en la cobertura vegetal em regiones semi-áridas. In: Aplicações de Geotecnologias na Engenharia Florestal. Ed., Attílio Antonio Disperati; João Roberto dos Santos. Curitiba, PR.; Copiadora Gabardo LTDA, 2004. p.61-69. (ISBN 85904724-1-8).

[3] F.D. Maldonado, and J.R. Santos. Metodología de detección de cambios utilizando técnicas de rotación radiométrica. In: Simpósio Brasileiro de Sensoriamento Remoto, 12. Goiânia (Brasil), 16-21 abr., 2005. INPE. Anais. [CDROM].

[4] F.D. Maldonado, and J.R. Santos. Minimização dos ruídos das Imagens CBERS através da inversão do algoritmo de classificação isodata em região de floresta amazônica. In: XIII Simpósio Brasileiro de Sensoriamento Remoto (SBSR). Florianópolis (Brasil), 21-26 abr., 2007. INPE. Anais. [CDROM].

[5] GUAMÁN, A. 1983. Estudio de Suelos de la Provincia Ñuflo de Chávez (Sector Ascensión de Guarayos)-Nivel de Reconocimiento. Corporación Regional de Desarrollo de Santa Cruz. 129 p.

[6] MUSEO DE HISTORIA NATURAL "NOEL KEMPF MERCADO", 1998. Diagnostico de la Biodiversidad y sugerencias estratégicas de gestión del Parque Botánico Guarayú, Santa Cruz - Bolivia.
[7] NAVARRO, G. 1992. Estudio de Parques Nacionales y otras Áreas Protegidas. En: Informe Final, Proyecto de Protección de Recursos Naturales en el Departamento de Santa Cruz.

[8] NAVARRO, G. 1997. Sinopsis de la Vegetación del Departamento de Santa Cruz, Bolivia. Sociedad Boliviana de Botánica 1(2): pp. 38-58.

[9] F.D. Maldonado, J.R. Santos, and V.C. Carvalho. Land use dynamics in the semiarid region of Brazil (Quixabá-PE): characterization by principal components analysis. International Journal of Remote Sensing, v.23, n.23, p.50055013, 2002. 